\title{
Economic Value of Genetic Merit of Dairy Semen ${ }^{1}$
}

\author{
Albert De Vries ${ }^{2}$
}

An easy way to rank dairy sires for profitability of their daughters is to compare their predicted transmitting ability (PTA) of an economic index such as USDA's lifetime Net Merit (NM\$). In certain markets, another index such as Cheese Merit, Fluid Merit, or Grazing Merit is more appropriate because the marginal values of improvement of some traits are different. These economic indexes are readily available. However, semen prices are not the same. The number of inseminations needed to produce a conception varies among sires. Considering differences in NM\$, price, and fertility, it is not immediately obvious which sire's semen is the best value. Alternatively, it is useful to determine the amount a dairy farmer can afford to spend on sires that differ in NM\$ or conception rate or both. Attempts to calculate the economic value of semen have been made since at least the 1970s. The basic calculations have since become available (Dechow 2016). This fact sheet reviews these calculations, adds a few other considerations, and offers estimates of the worth of the genetics of dairy semen. A spreadsheet where the user can vary inputs and observe the effect on the economic value of genetic merit of dairy semen is also provided.

Example: There are two sires with PTA for NM\$ that differ by $\$ 100$. The NM $\$$ is a lifetime index, which suggests that the daughter of one sire is $\$ 100$ more profitable than the daughter of the other sire during her productive lifetime. USDA has standardized this lifetime at 2.78 lactations, or approximately 3 years (VanRaden 2017).
The NM\$ value is currently based on USDA's estimates of the marginal economic values of changes in 13 traits in the next several years. This includes values for protein, fat, beef, feed, and replacement prices. These values make sense, but markets often change. For example, all four indexes assume that 1 pound more fat has a value of $\$ 2.00$, but the price of fat is not $\$ 2.00$ today. However, today's insemination decision may result in a calf that does not start producing until almost 3 years from today. Therefore, today's market prices are not so relevant. We do not know if, on average, the NM\$ (or another index) over- or underestimates the real differences in profitability, or perhaps is right. For this example, we assume that a difference of $\$ 100$ in NM\$ results in an actual profit difference of $\$ 100$ between the daughters.

It is important to note that not every insemination results in a pregnancy. To start our calculations, we need the conception rate of the female being inseminated as well as the sire conception rate (SCR) of the sire. For example, a sire with an SCR of $+2 \%$ elevates the conception rate by 2 percentage points. Heifers generally have greater conception rates than cows. Let us assume for now that the SCR is 0 and the female's conception rate is $35 \%$. If conception is achieved, there is still a risk of abortion and subsequent culling. We will assume both risks are $5 \%$. Once a calf is produced, the calf must be alive in order for the genetic merit of the semen to have value. Stillbirth is already included in the calving ability trait in the NM\$ index, so it is not included again to avoid double counting. Next, we will assume that only female calves benefit from differences

1. This document is AN338, one of a series of the Department of Animal Sciences, UF/IFAS Extension. Original publication date January 2018. Visit the EDIS website at http://edis.ifas.ufl.edu.

2. Albert De Vries, professor, Department of Animal Sciences; UF/IFAS Extension, Gainesville, FL 32611.

The Institute of Food and Agricultural Sciences (IFAS) is an Equal Opportunity Institution authorized to provide research, educational information and other services only to individuals and institutions that function with non-discrimination with respect to race, creed, color, religion, age, disability, sex, sexual orientation, marital status, national origin, political opinions or affiliations. For more information on obtaining other UF/IFAS Extension publications, contact your county's UF/IFAS Extension office. 
in genetic merit. In other words, the differences in $\mathrm{NM} \$$ do not affect the value of male calves. Here we will assume that the probability of a female calf is $48 \%$. Sexed semen would make this probability much greater. Next, the female calf has a risk of being culled in her young stock period before production starts. We will also put this risk at $5 \%$. Now all important factors that determine if an insemination results in a producing cow are presented.

Remember that the NM\$ index value applies to a daughter $(1 \times \$ 100)$ but does not include the value that this daughter passes on to her daughters $(0.5 \times \$ 100=+\$ 50)$, granddaughters $(0.25 \times \$ 100=+\$ 25)$, and all later generations (small fractions of $\$ 100$ ). Every generation receives half the genetic merit of the previous generation. The sum of these "gene flow" multipliers is 2, but it also depends on the number of future female offspring of the daughter. We will assume that every female produces one replacement. However, these expected genetic gains are realized in the future, so they need to be adjusted to be put into current prices. For example, the $+\$ 100 \mathrm{NM} \$$ is not realized until approximately 4 years after the insemination. This discount factor for all future generations is roughly 0.65 , so the combined effect of gene flow and discounting is $2 \times 0.65=$ 1.3. In other words, the $\$ 100 \mathrm{NM} \$$ is worth $\$ 130$ in today's dollars, provided the insemination results in a cow that starts production.

Now we can calculate the value of $+\$ 100 \mathrm{NM} \$$ difference in the two units of semen using the factors explained above, as $+\$ 100 \times 35 \% \times(1-5 \%) \times(1-5 \%) \times 48 \% \times(1-5 \%) \times 1.3$ $=\$ 18.73$. A dairy farmer could afford to pay up to $\$ 18.73$ more per unit of semen that is $+\$ 100$ higher in NM\$ and has the same SCR. If this semen is used in heifers with a conception rate of $60 \%$, the value increases to $\$ 32.10$. Genetic differences are more valuable in females with high conception rates because fewer inseminations are needed to achieve a pregnancy. Sexed semen also leads to greater values. Using a $90 \%$ chance of a female calf instead of $48 \%$, the value increases to $\$ 35.11$ when conception rate is $35 \%$. The value increases much more if the female is an embryo donor.

Differences in SCR cause differences in the overall conception rate and affect the change in and cost of days open. Days open after an insemination that did not result in a conception depend on the service rate (speed of re-breeding) and the conception rate. Low service rates and low conception rates mean more days open and greater economic loss for a missed conception. The average cost of a day open is roughly $\$ 2.50$, but it depends greatly on the situation. An insemination late in lactation has a high cost per day open (roughly \$5), so the value of a 1-point greater SCR is worth a lot late in lactation. An early first insemination in a high-producing cow has a low cost per day open (close to \$0). Figure 1 shows the value of semen for SCR of $-1 \%, 0 \%$, and $+1 \%$ using a cost of $\$ 2.50$ per day open and a service rate of $50 \%$. It is clear that differences in SCR at low female conception rates are more important than at high conception rates.

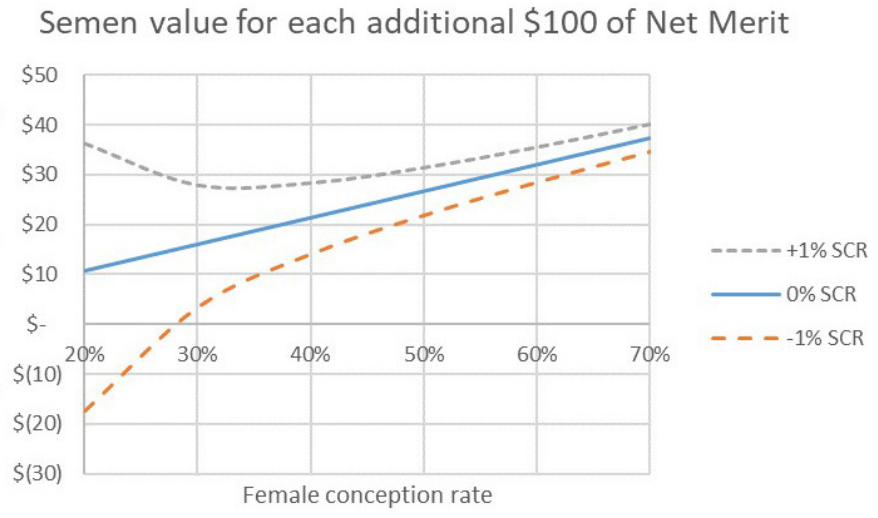

Figure 1. Semen value for each additional $\$ 100$ of Net Merit for varying female conception rates and three levels of sire conception rates (SCR).

Credits: Albert De Vries, UF/IFAS

The formulas can also be used to compare two sires directly. For example, sire A has a PTA of NM\$ of $\$ 800$ and sire B has a PTA of NM $\$$ of $\$ 700$. The SCR of sires A and B are $0 \%$ and $+1 \%$, respectively. Semen of sire A costs $\$ 20$ per unit and semen of sire B costs $\$ 10$ per unit. Therefore, the genetic merit of sire $\mathrm{A}$ is greater, but the fertility and cost per unit of semen of sire B are better. We will use all the aforementioned assumptions that led to the $\$ 18.73$ net present value calculation. In this example, the net present value of the $\$ 800 \mathrm{NM} \$$ semen is $\$ 149.80$ and the net present value of the $\$ 700 \mathrm{NM} \$$ semen is $\$ 143.15$. As a result, sire $A$ has a genetic value advantage of $\$ 6.65$, but also has a $\$ 10$ greater cost per unit of semen. Semen from sire B is worth $\$ 3.35$ more than semen from sire $A$ and is the better deal for the dairy farmer.

There are three other factors that can affect the value of semen. The first is the reliability of the PTA of NM\$. A lower reliability means more uncertainty about the true genetic merit of the semen. The expected value of $+\$ 100$ is independent of the reliability, but a risk-averse dairy farmer would prefer higher reliability to lower reliability. Dairy farmers who are willing to take risks, on the other hand, would prefer the lower reliability. It is difficult to quantify 
the extent to which attitude towards risk affects the amount a dairy farmer is willing to pay for semen.

A second factor is response to selection. We have assumed that the difference in PTA of $+\$ 100 \mathrm{NM} \$$ between two bulls results in a true genetic difference of $\$ 100$. The response is likely greater on farms where females are well cared for. A greater response to selection increases the value of semen.

Finally, the NM\$ and other USDA indexes are standardized at 2.78 lactations. This corresponds to a cow cull rate of approximately $33 \%$. On farms with a greater cull rate, the cow has fewer lactations to express her genetic merit, and will have fewer daughters. For example, if the cow had only 1.78 lactations, then the $\$ 100 \mathrm{NM} \$$ is worth approximately $\$ 64$. This estimate is approximate because gene flow and discounting change, and the current $\mathrm{NM} \$$ formula contains heifer conception rate which is independent of the number of lactations. In general, a higher cull rate decreases the value of semen. Other factors could also affect the value and choice of semen, such as the amount of relatedness between the sire and female.

In conclusion, a difference in the genetic merit is probably worth more than many dairy farmers may think. A spreadsheet with the formulas and factors described above is available at http://dairy.ifas.ufl.edu/tools.

\section{References}

Dechow, C. 2016. "How much can we pay for high-end bulls?" Hoard's Dairyman 161: 130.

Rogers, G. W. 1990. "A utility function for ranking sires that considers production, linear type traits, semen cost, and risk." Journal of Dairy Science 73: 532-538.

VanRaden, P. M. 2017. "Net merit as a measure of lifetime profit: 2017 revision.” USDA AIP Research Report NM\$6 (2-17). Accessed on December 13, 2017. https://www.aipl. arsusda.gov/reference/nmcalc-2017.htm 